\title{
Patterns of Cell Movement within the Dictyostelium Slug Revealed by Cell Type-Specific, Surface Labeling of Living Cells
}

\author{
Tomoaki Abe, * Anne Early," Florian Slegert,, \\ Cornells Weljer, $t$ and Jeffrey Williams* \\ "Imperial Cancer Research Fund \\ Clare Hall Laboratories \\ South Mimms \\ Hertsfordshire EN6 3LD \\ England \\ tZoologisches Institut \\ Ludwig-Maximilians-Universităt \\ 80333 München \\ Federal Republic of Germany
}

\section{Summary}

There are cells scattered in the rear, prespore region of the Dictyostelium slug that share many of the properties of the preatalk cells and that are therefore called anterior-like cells (ALCs). By placing the gene encodIng a cell surface protein under the control of an ALCspecific promoter and Immunologically labeling the Ilving cells, we analyze the movement of ALCs within the slug. There is a posterior to anterior cellular flow, and the ALCs change their movement pattern as they enter the prestalk zone. Prestalk cells are periodically shed from the migrating slug. They must be replaced If the correct ratio of prestalk to prespore cells is to be maintained, and we present evidence for the transdifferentiation of prespore into prestalk cells, with ALCs functioning as intermediates in the transition. The slug has, therefore, a surprisingly dynamle structure, both with respect to cellular differentiation and cell movement.

\section{Introduction}

Pattern formation usually involves a combination of cellular differentiation and directed cell movement. While there are recent indications that some of the same classes of genes that control differentiation also function in morphogenetic cell movement (Salser and Kenyon, 1992; Montell et al., 1992; Niehrs et al., 1992), directed cell migration is not well understood. Here, Dictyostelium has much to offer, because cell motility and chemotactic movement towards CAMP during cellular aggregation are very well characterized and this provides a starting point from which to understand morphogenesis during the subsequent, multicellular stages of development. The Dictyostelium aggregate is a three-dimensional structure containing up to 100,000 cells, and thus far it has not been possible to trace the movement within it of stably marked, specific cell types. We describe a method of overcoming this limitation and apply it to a subtype of the prestalk cells and to the prespore cells.

The slug is composed of a cylindrical mass of prespore cells, constituting the rear four-fifths of slug length, with a tapering mass of prestalk cells at the anterior. Prestalk cells, which comprise about $13 \%$ of cells within the slug (Sternfeld and David, 1982), are stained selectively by vital dyes such as neutral red (Bonner, 1952). Interspersed among the prespore cells in the posterior region are cells that stain with vital dyes and that are therefore called anterior-like cells (ALCs) (Sternfeld and David, 1981, 1982). There are approximately as many ALCs in the prespore region as there are anterior prestalk cells (Sternfeld and David, 1982). The ALCs have been proposed to play a role in determining the ratio of prestalk to prespore cells within the migrating slug, by acting as intermediary cells with the option of converting to become either prestalk or prespore cells (Blaschke et al., 1986).

Several pieces of evidence suggest that ALCs and the anterior prestalk cells are potentially interchangable cell populations. This can be most graphically demonstrated by surgically removing the prestalk region, whereupon ALCs are recruited to replace the missing prestalk cells (Sternfeld and David, 1982). Grafting experiments also show that ALCs are continually moving forward into the prestalk zone during normal slug migration (Bonner, 1957; Francis and O'Day, 1971; Kakutani and Takeuchi, 1986). When the rear of a vitally stained slug was grafted to an unstained front, Bonner (1957) found stained cells in the tip within $6 \mathrm{hr}$, Francis and O'Day (1987) estimated that $1.6 \%$ of cells cross such a graft boundary every hour, and Kakutani and Takeuchi (1986) found that within $10 \mathrm{hr}$ after grafting about $30 \%$ of cells in the prestalk zone derived from ALCs.

While there is this potential for positional interchange and for trans-differentiation when the aggregate is forced to regulate, the ALCs and anterior prestalk cells have generally been believed to be discrete cell types, because they differ in their patterns of gene expression (Devine and Loomis, 1985) and they adopt different fates when the fruiting body forms at culmination. During culmination, the ALCs move to surround the spore head to form cups that cradle it, and they also form the outer part of the basal disc, the structure that supports the stalk (Sternfeld and David, 1982; Jermyn and Williams, 1991; Sternfeld, 1992). In contrast, the prestalk cells move into the stalk tube where they vacuolate and die (Raper and Fennell, 1952).

Vital dyes provide valuable markers, especially for tracing the movements of living cells. However, staining is dependent upon selective dye accretion in intracellular vesicles. This is a potentially transitory difference, and therefore, in this respect, genetic markers provide more reliable tools. Two genes encoding extracellular matrix proteins, the $\theta \mathrm{CmA}$ and the $\theta \mathrm{CmB}$ gene, have provided ALC-specific markers (Ceccarelli et al., 1991, Gaskell et al., 1992), and there are also ALC-specific markers derived from genes involved in intracellular signal transduction (Hadwiger and Firtel, 1992; Howard et al., 1992).

The ecmA and ecmB genes encode closely related proteins that form part of the slime sheath, the matrix that surrounds the migrating slug, and the stalk tube, the protein and cellulose containing matrix that envelops the stalk 
cells (McRobbie et al., 1988). The ecmA gene is expressed in some of the ALCs and in all the cells in the prestalk region (Gaskell et al., 1992; Jermyn et al., 1989). It is, however, more strongly expressed in the anterior half of the prestalk region, in cells termed pstA cells, than in the cells that occupy the rear half of the prestalk region, the pstO cells (Jermyn et al., 1989; Jermyn and Williams, 1991). Two separate regions within the ecmA promoter are independently able to direct expression within pstO cells, while a region proximal to the cap site is necessary for expression in pstA cells (Early et al., 1993). The ecmB promoter is also complex, in that one subfragment directs expression in the subset of ALCs that move above the spore head at culmination (Ceccarelli et al., 1991).

Analysis of ecmA and ecmB gene expression shows there to be a surprisingly wide spectrum of prestalk-like cell types in the prespore region of the migrating slug. There are cells in the prespore region that express either the $\theta \mathrm{cm} A$ gene or the $\theta \mathrm{cmB}$ gene, and there are cells that express both genes (Jermyn and Williams, 1991; Gaskell et al., 1992). Colocalization studies with neutral red show that there are ecmA-or ecmB-expressing cells that do not stain with vital dyes and also that there are neutral red staining cells that appear to express neither marker (Gaskell et al., 1992). It is probably, therefore, very misleading to attempt to lump together all the ALCs, and here we concentrate on one specific subset of the ALCs, which are defined by their ability to utilize a specific subregion of the ecmA promoter.

In all ecmA promoter constructs in which expression occurs selectively in pstO cells (we term these ecmO constructs), there is also expression in scattered cells within the prespore region (Early et al., 1993). This suggests the possibility of a kinship between pstO cells and the ecmOexpressing subset of the ALCs. One method of establishing the relationship between cells located in different parts of a structure is to determine whether they form part of an interchanging population. Here, we investigate the movement of living pstO cells, by marking them with a fluorescent label. We show that in grafting and cell reaggregation experiments the ecmO-expressing subset of the ALCs move forward to form a band of cells at the prestalk-prespore boundary, supporting the notion that they are identical to the pstO cell type.

The establishment of this in vivo labeling method has also allowed us to apply recently developed methods of tracing the movement of living cells within the slug (Siegert and Weijer, 1991, 1992) to study the movement of specific cell types. Previous studies using vital dyes showed that, during slug migration, individual ALCs in the prespore region move directly forward, along the long axis of the slug (Siegert and Weijer, 1991, 1992). In contrast, the cells in the prestalk region move around the long axis of the slug tip where their movements follow a scroll wave (Siegert and Weijer, 1992; Steinbock et al., 1993). We show, using time lapse video microscopy, that ecmo-expressing cells in the back and front of the slug show this same differential movement pattern.

Finally, by performing in vivo labeling with a presporespecific marker, we show that prespore cells continuously dribble forward into the prestalk zone during slug migration and that some of the cells expressing the ecmo fusion gene are trans-differentiated cells that derive from cells that had previously expressed a prespore-specific marker. Based upon these observations, we propose a scheme for the pattern of cellular movement and trans-differentiation within the migrating siug.

\section{Results}

\section{Establishment of a Method for Labeling the Surface} of Living Dictyostelium Cells

To be able to identify specific cell types within a mixed population of living cells, we have established a technique in which a reporter gene product is caused to accumulate at the surface of cells where it can be labeled using a fluorescent antibody.

The PspA protein is specifically expressed by prespore cells (Chung et al., 1981; Gregg et al., 1982; Early et al., 1988), in which it is linked to the cell surface by a glycolipid anchor (Ti et al., 1990). The pspA-c-myc construct contains an epitope tag, derived from the human c-myc oncogene (Evan et al., 1985), inserted into the pspA gene (Early et al., 1988). This construct directs expression of the PspA-c-Myc fusion protein to the surface of prespore cells. To study prestalk cell movement, the pspA promoter was replaced by prestalk-specific control elements. The ecmA-c-myc construct contains the entire ecmA promoter, coupled to the pspA-c-myc coding region, and ecmO c-myc is an analogous construct containing a subfragment of the ecmA promoter that directs expression only in pstO cells. (Figure 1; please note that while it has proven straightforward to construct lac $Z$ fusion genes that are expressed only in pstO cells [Early et al., 1993], it has not as yet proven possible to generate a construct that is only expressed in pstA cells. Hence, we were not able to study the movement behavior of individual pstA cells.)

The ecmA-c-myc and ecmO-c-myc constructs were introduced into Dictyostelium cells, and stable transformants were selected. To show that the two constructs were correctly expressed, developing cells were fixed and stained with 9E10, the monoclonal antibody that recognizes the c-Myc epitope present in pspA-c-myc (Evan et al., 1985). The pattern of expression is identical to that observed with lacZ fusion genes (Figure 2; Early et al., 1993): the ecmAc-myc construct is expressed in pstA cells, in psiO cells, and in scattered cells in the rear of the slug, while the ecmo-c-myc construct is expressed only in the latter two populations. Staining of disaggregated, fixed cells showed that the fusion protein is primarily located at the cell surface (data not shown).

Having established that the fusion genes were correctly expressed, we devised a method whereby the protein can be detected on living cells. Cells expressing the ecmAc-myc construct were allowed to develop to the slug stage, disaggregated, and incubated with fluorescently labeled $9 E 10$ antibody. The c-Myc fusion protein becomes fluorescently labeled and is initially located at the surface of the cells (Figure 3a). Although it becomes internalized over the next few hours (Figure 3b), the fluorescence remains 
a

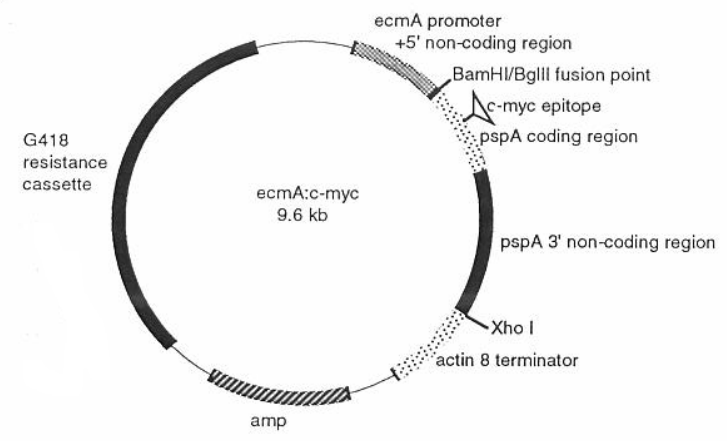

b

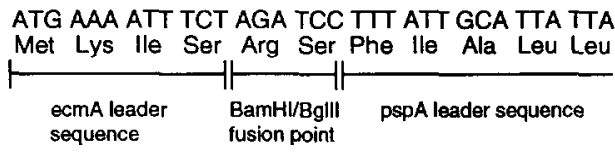

C

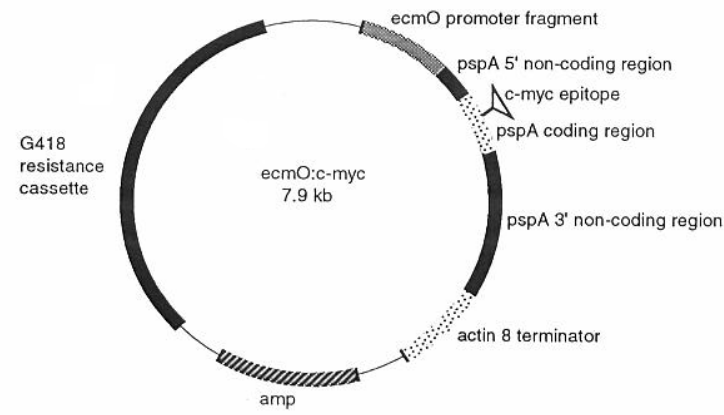

Figure 1. The Structure of the ecmA-c-myc and ecmo-c-myc Constructs

(a) The ecmA-c-myc construct. The 4.3 clone, which contains the pspA gene and its flanking sequences (Earty et al., 1988), was used in polymerase chain reaction (PCR) with an oligonucleotide that anneals to a region surrounding the initiation codon of the pspA gene. This oligonucletide was designed to insert a BamHI site into the leader sequence (see [b]), and it was used in PCR in combination with an oligonucleotide that anneals downstream of the gene, at the junction of the Dictyostelium insert with the vector sequences (Early et al., 1988). There is a Xhol site $1 \mathrm{~kb}$ downstream of the PspA gene, and the PCR product was cleaved with BamHI and Xhol to generate a 1.8 $\mathrm{kb}$ fragment containing the gene. This fragment was ligated with the Bglll and Xhol digest of $\theta \mathrm{cmA}$-neo-lacZ (D. Traynor, personal communication), a vector that contains an $\theta \mathrm{cmA}-\mathrm{tac} Z$ fusion gene (Jermyn and Williams, 1991) and that also contains a G418 resistance cassette. Bglll-Xhol digestion cleanly excises the lacZ gene to leave the ecmA promoter, $5^{\prime}$ noncoding region, and the first few amino acids of the ecmA leader sequence (see [b]). The termination-polyadenylation sequences from the Dictyostelium actin 8 gene lie downstream of the Xhol site, but the temination-polyadenylation signals present within the pspA downstream sequences presumably act to direct processing of the transcript.

(b) The $\theta \mathrm{cmA}-p \operatorname{spA}$ junction sequences in the $\theta \mathrm{cmA-c}-m y c$ construct. (c) The ecmo-c-myc construct. This derives from an ecmo-specific lacZ fusion construct, construct $G$ in Early et al. (1993), that contains the region between nucleotides -1694 and -1048 (numbered relative to the cap site) of the ecmA promoter. First, the BamHI site at the $3^{\prime}$ end of the $\theta \mathrm{cmA}$ promoter sequences in construct $\mathrm{G}$ was cleaved and
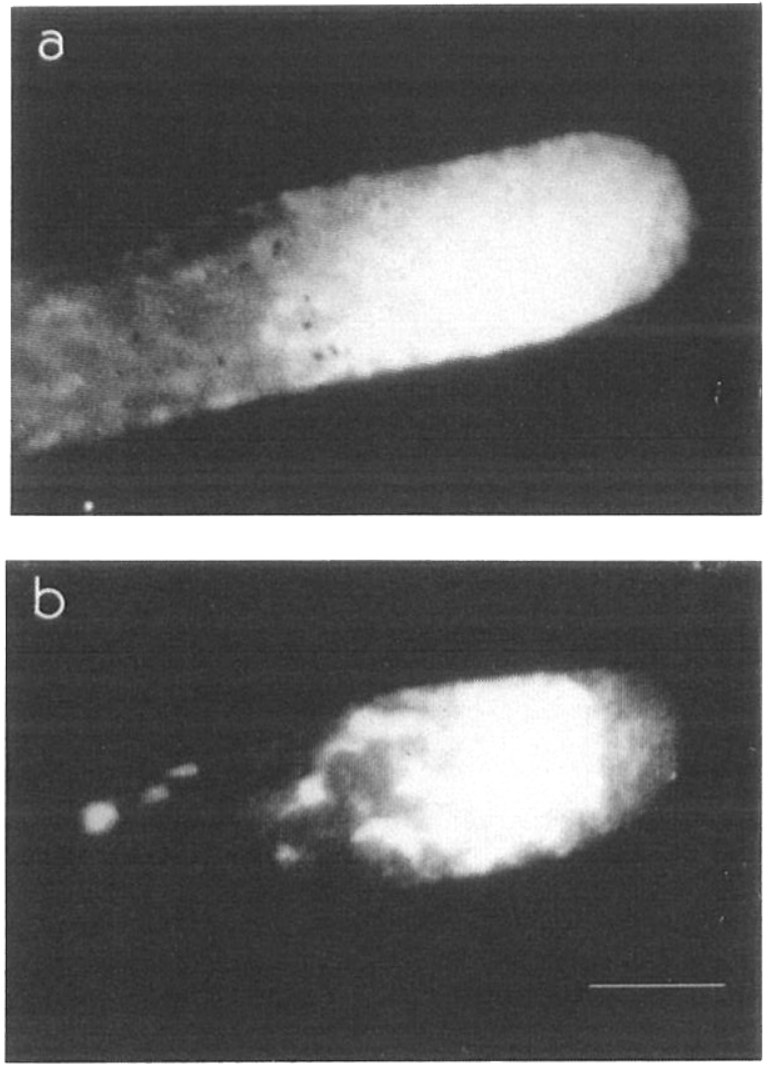

Figure 2. Analysis of the Expression Patterns of the ecmA-c-myc and ecma-c-myc Transformants Using Fixed Material

ecmA-c-myc and ecmO-c-myc transformant cells were allowed to develop to the first finger stage, were fixed and indirectly stained with anti-human c-myc monoclonal antibody 9E10, and were TRITClabeled goat anti-mouse IgG as described in Experimental Procedures. (a) ecmA-c-myc transformant. (b) ecmo-c-myc transformant. The scale bar represents $50 \mu \mathrm{m}$.

readily detectable for at least $24 \mathrm{hr}$ using a sensitive video camera. When the c-Myc fusion protein is internalized, it accumulates in vesicular structures so that the signal strength actually increases over the first few hours after labeling. After internalization, the amoebae appear as diffuse, weakly fluorescent cell outlines containing several intensely fluorescent spots (Figure 3b).

\section{After Reaggregation, Fluorescently Labeled Cells Migrate to Their Correct Respective Positions within the Aggregate}

To study the behavior of labeled living cells, we took advantage of the fact that disaggregated cells readily reaggregate when placed in proximity on a suitable substra-

end filled, and then the Xhol site, located $3^{\prime}$ to the lecZ sequences, was cleaved. Finally, a Hindlll (end-filled)-Xhol fragment, containing the entire c-myc marked pspA gene and 127 nt upstream of the pspA cap site (Early and Williams, 1989), was inserted. The upstream pspA sequences are nonfunctional in directing cell type specific gene expression (this is directed by the $\theta \mathrm{cmO}$-specific sequences), but they provide a cap site and TATA box. 

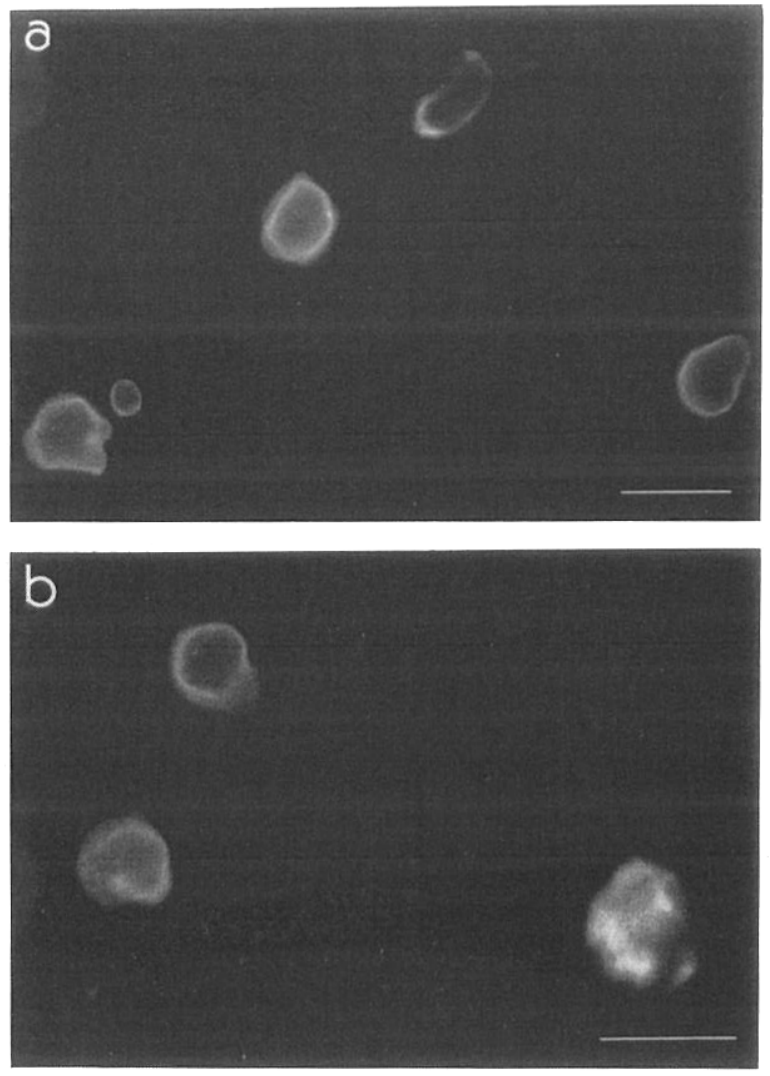

Figure 3. Subcellular Localization of the c-Myc Fusion Protein in Living Cells

ecmA-c-myc transformant cells were allowed to develop to the slug stage, disaggregated, and labeled with TRITC-conjugated 9E 10 monoclonal antibody as described in Experimental Procedures. (a) Cells viewed by fluorescence microscopy immediately after labeling. (b) Cells viewed after $1 \mathrm{hr}$ of incubation. The scale bars represent $20 \mu \mathrm{m}$.

tum. They yield a tight aggregate within $3-4 \mathrm{hr}$ and a migratory slug within $6-8 \mathrm{hr}$, whereas slug formation normally takes at least $12 \mathrm{hr}$. Cells subjected to the immunofluorescence labeling procedure described above reaggregate at the same rate as similarly treated, unstained controls.

During normal slug formation, cells expressing the $\Theta \mathrm{cmA-}$ lacZ fusion gene (i.e., the pstA and pstO cells, since this reporter construct does not allow distinction between the two cell types) arise at apparently random positions within the cell mass and migrate upwards to form the tip (Williams et al., 1989). In ecmA-c-myc transformants undergoing reaggregation, the expressing cells also accumulate within the tip to yield a slug with a structure identical to that of a fixed and stained aggregate (compare Figure $4 a$ with Figure 2a). The fact that the fluorescently labeled ecmA-expressing cells migrate to the apex of the aggregate, just as they do during normal slug formation, suggests that they retain their state of differentiation during the approximately $45 \mathrm{~min}\left(\right.$ at $4^{\circ} \mathrm{C}$ ) of the disaggregation and labeling procedures.

The behavior of pstO cells is more complex, but, again, the cells retain their sorting preferences. During slug formation, cells expressing the ecmO-lacZ fusion gene appear at random positions within the aggregate and then accumulate proximal to the prestalk-prespore boundary (Early et al., 1993). If the aggregate culminates in situ, the pstO cells remain in this position and so are the last cells to enter the stalk tube. If the slug migrates away from its site of formation, ecmO-expressing cells are found within the anterior tip, i.e., within the pstA region (Early et al., 1993). Similarly, after in vivo labeling, ecmo-expressing cells initially accumulate at the prestalk-prespore boundary (Figures $4 \mathrm{~b}$ and $5 \mathrm{a}$ ), but after a period of slug migration they become distributed throughout the prestalk region (Figure 5b).

In the experiments that follow, this disaggregation-labeling-reaggregation protocol was used to prepare slugs in which ecmO-expressing cells were fluorescently tagged. For convenience, we will term these ecmO* slugs.

\section{The ecmO-Expressing Subset of ALCs and the Psto Cells Form a Potentially Interchanging Population}

To determine whether ecmo-expressing cells within the prespore zone can move forward to form part of band of pstO cells at the prestalk-prespore boundary, the rear halves of ecmO* slugs were disaggregated and allowed to reaggregate. To observe the movements of the labeled cells clearly, they were mixed with a 5-fold excess of unlabeled slug cells. In the standing slug, some of the fluorescent cells are scattered throughout the prespore zone, and some of them are clustered at the prestalk-prespore boundary, the position occupied by the pstO cells (Figure 5a). Thus, when allowed to reaggregate, some of the ecma expressing cells from within the prespore zone join with the pstO cells at the prestalk-prespore boundary. If the aggregates are allowed to form migratory slugs, then, as expected (Early et al., 1993), the fluorescently labeled ecmO-expressing cells become distributed throughout the prestalk zone (Figure 5b).

We also performed grafting experiments in which the rear halves of ecm * slugs were fused to the front portions of unlabeled slugs. The labeled cells move forward into the anterior half of the grafted slugs, eventually to become concentrated at the prestalk-prespore boundary. Again, as the slugs migrate away from their site of formation, the labeled ecmO-expressing cells become scattered throughout the prestalk region (Figure 6). In some slugs, there is also a concentration of ecmo-expressing cells at the rear of the slug (data not shown). Such an accumulation of ALCs is often seen in normal slugs, and the structure so formed is called the rearguard. It may result from an abortive attempt at culmination because, during culmination, a subset of the ALCs move basipetally to form the outer part of the basal disc (Sternfeld and David, 1982; Jermyn and Williams, 1991; Sternfeld, 1992).

Since the reaggregation and grafting experiments show that the subset of the ALCs that are able to express an ecmO construct have the potential to move to the the position normally occupied by the pstO cells, we will henceforth 

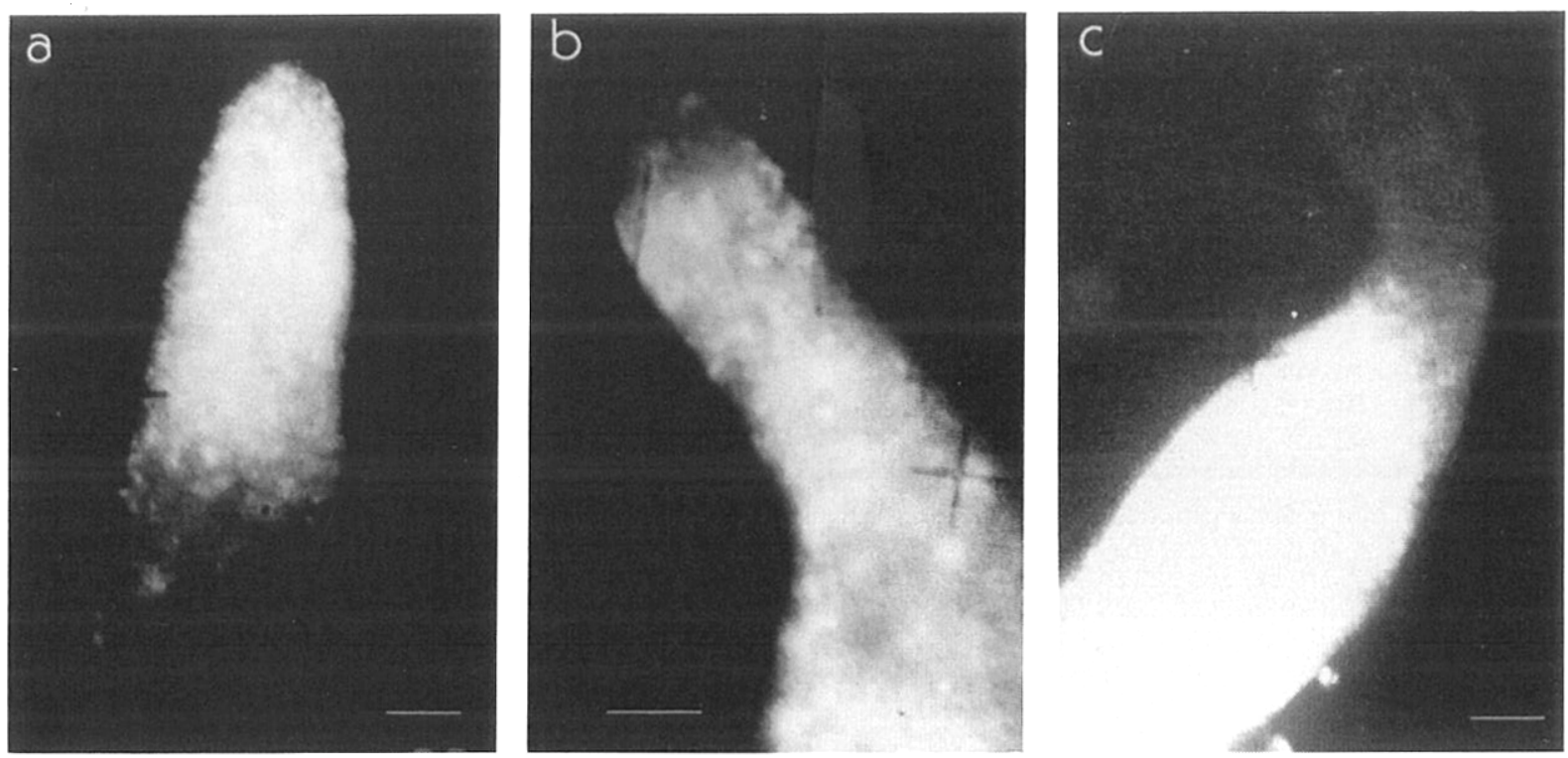

Figure 4. Reaggregation of In Vivo Labeled Cells

Migratory slugis derived from ecmA-c-myc transformant cells (a), and aggregates at the first finger stage of development derived from psto-c-myc (b), or pspA-c-myc (c) transformant cells, were mechanically disaggregated. The dissociated cells were labeled in vivo with TRITC-labeled 9E10 monoclonal antibody and allowed to reaggregate. These are images of the resultant aggregates at the first finger stage of development, viewed using a fluorescence microscope coupled to a video camera and recorder: (a) aggregate derived from ecmA-c-myc transformant cells, (b) aggregale derived from ecmo-c-myc transformant cells, (c) aggregate derived from pspA-c-myc transformant cells. The scale bars represent $25 \mu \mathrm{m}$.

use the collective term pstO/ALC for both populations of cells.

\section{During Slug Migration Prespore Cells Move Forward into the Prestalk Zone}

The above experiments provide evidence for a gradual forward flow of pstO/ALCs into the pstA region during slug migration. If the correct ratios of cell types within the slug are to be maintained, there must be a compensatory transdifferentiation and forward movement of prespore cells into the psto region. There is evidence favoring the existence of such a movement because cells that express the pspA-lacZ fusion gene appear in the prestalk region during slug migration (Harwood et al., 1991). However, it
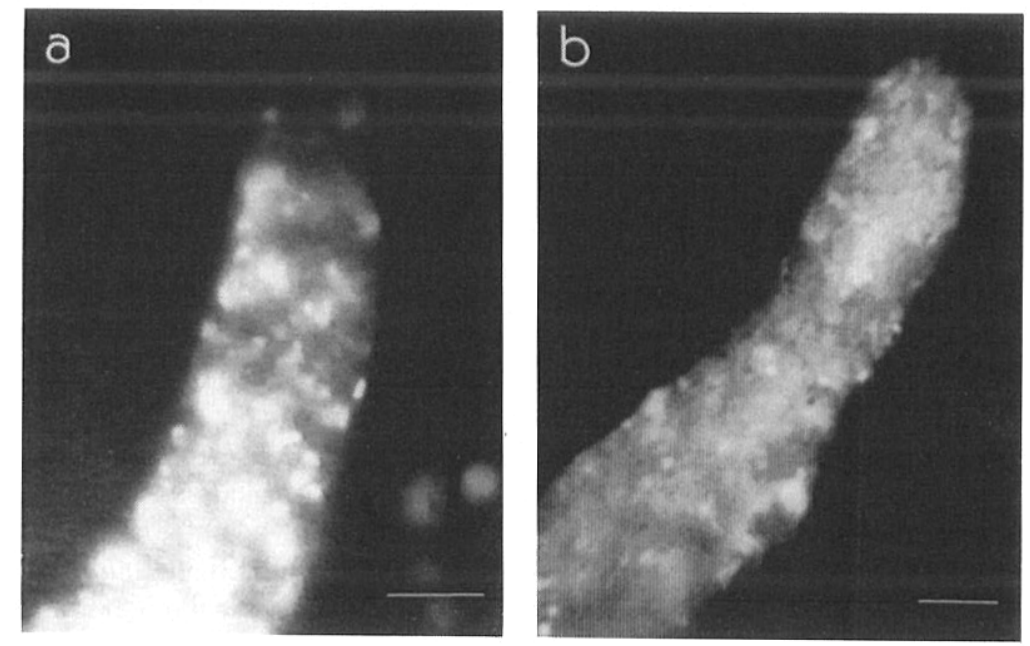

Figure 5. Coaggregation of Fluorescently Labeled Cells Derived from the Rear of the Slug with Unlabeled Cells

ecmo-c-myc transformant cells were developed to the first finger stage of development and mechanically disaggregated. The dissociated cells were then labeled in vivo with TRITClabeled 9E10 monoclonal antibody and allowed to reaggregate to yield $\theta \mathrm{CmO}$ * slugs. The posterior halves of such slugs were excised, disaggregated, and mixed with a 5-fold excess of nonlabeled AX-2 slug cells. The mixed cell population was allowed to reaggregate on agar plates, and the resultant structures were viewed in the fluorescence microscope. (a) A newly reformed first finger. (b) A migrating slug. The scale bars represent $25 \mu \mathrm{m}$.

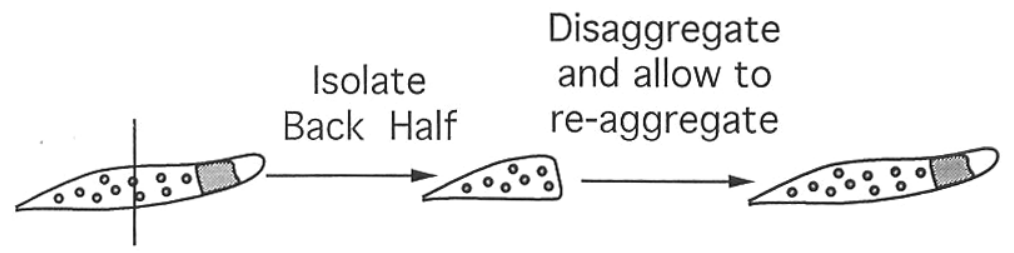



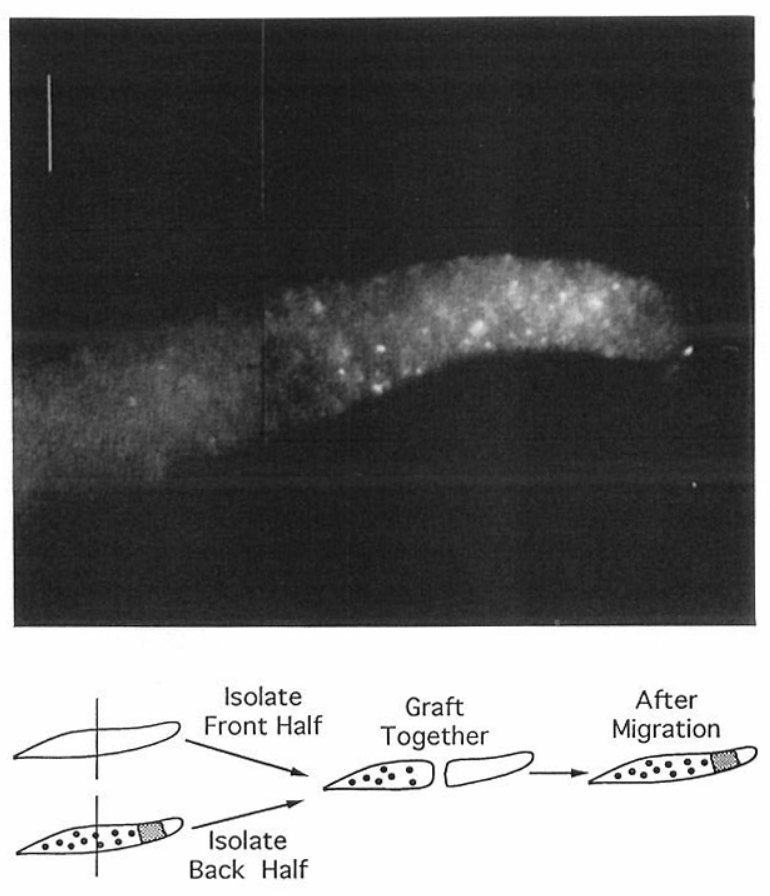

Figure 6. Grafting of the Back of an $\theta \mathrm{cmO}$ * Slug onto the Front of an Unlabeled Slug

The posterior halves of $\theta \mathrm{cmO} \mathrm{O}^{*}$ slugs (see text and legend to Figure 5), which had migrated for $9-12 \mathrm{hr}$ at $22^{\circ} \mathrm{C}$, were grafted onto equivalently treated nonstained slugs, using a hair loop. Grafted slugs were incubated at $22^{\circ} \mathrm{C}$ for $3-9 \mathrm{hr}$ and observed in the fluorescence microscope. This picture was taken after $6 \mathrm{hr}$ of incubation. The scale bar represents $50 \mu \mathrm{m}$.

was not previously possible to decide whether there is forward movement of prespore cells into the prestalk zone or whether anteriorly located prestalk cells trans-differentiate in situ into prespore cells. Hence, we have reinvestigated this phenomenon by in vivo labeling, using as a prespore marker the pspA-c-myc fusion gene (Early et al., 1993).

When transformant cells containing the $p s p A-c-m y c$ fusion gene are disaggregated, labeled with the 9E10 antibody, and allowed to reaggregate, the resultant standing slugs (pspA* slugs) show a very clear demarcation between the prestalk and prespore zones (see Figure 4c). However, after a few hours of migration, fluorescent cells appear within the prestalk region of $p s p A^{*}$ slugs. Initially, there is an elevated concentration of such cells within the pstO region (Figure 7), but the fluorescently labeled cells eventually come to occupy the entire tip (data not shown).

\section{A Fraction of the Prespore Cell Population Trans-Differentiates into PstO/ALCs}

The above observations confirm results obtained using the pspA-lacZ construct (Harwood et al., 1991), but go further by showing that prespore cells physically move forward into the prestalk zone. However, even after extended periods of migration, such labeled cells constitute only a minor fraction of cells within the tip (Figure 7; Harwood et al., 1991) and so would not be easily detectable using a prestalk-specific marker. It is therefore important to determine whether they are translocated prespore cells or cells that have trans-differentiated into prestalk cells. We provide evidence supporting the latter notion by showing that there are fluorescently labeled cells within the anterior half of $p s p A^{*}$ slugs that express an ecmO-lacZ construct. (Note that we chose to use ecmO as a marker, rather than ecmA, because this would show whether the trans-differentiation route for prespore cells lies via the pstO/ALCs.)

A double transformant containing the $p s p A-c-m y c$ and the ecmO-lacZ fusion gene constructs was subjected to in vivo labeling, and the cells were allowed to reaggregate to form $p s p A^{*}$ slugs. After a period of migration, the anterior halves of such slugs were excised and disaggregated, and the cells were allowed to attach to a microscope slide. The positions of the fluorescently labeled cells were recorded using a video microscope, and the cells were overlaid with fixative before being stained for $\beta$-galactosidase activity (Figure 8). In this particular experiment, about 10\% of the fluorescently labeled cells express the ecmO-lacZ fusion gene, but the fraction of such cells increases with the time of slug migration.

Thus, there exist within a $p s p A^{*}$ slug cells that express (or at some previous time had expressed) the pspA gene but that also express an ecmO-specific construct. This supports the notion that the "prespore" cells that move into the anterior prestalk zone trans-differentiate into prestalk cells.

\section{Quantitative Analysis of PstO/ALC and Psp Cell Movement In Vivo}

The ability to label living cells selectively has enabled us to extend recently developed methods of quantitatively analyzing cell movement (Siegert and Weijer, 1991, 1992) to study the behavior of pstO/ALCs. The movement of in vivo labeled cells expressing the ecmo-c-myc construct was recorded by very low light level, time-lapse video microscopy. Cell movement was analyzed by digital image processing, either by interactive manual tracking of labeled cells or by applying an algorithm that detects particle flow in the stored video sequences.

PstO/ALCs in the pstO region move around the long axis of the slug tip (Figures $9 \mathrm{a}$ and $9 \mathrm{~b}$ ). Measurement of many slugs shows very clearly that within the pstO region their movement describes a simple rotation (Figure 9a), even if the movement sometimes appears to take the form of counter rotating strands of cells (Figures $9 \mathrm{~b}, 9 \mathrm{e}$, and 9f). This latter type of apparent movement is due to the fact that the tip of the slug is most often lifted up in the air, and therefore the plane of focus cuts through the tip. This results in the simultaneous observation of cells at the upper and lower surfaces in the back and front of the prestalk zone, respectively.

The pstO/ALCs within the prespore region differ radically in their movement patterns from the pstO/ALCs in the prestalk region. In the prespore region, they mimic the behavior of the prespore cells by moving in the direction of migration of the slug, i.e., along its long axis (Figures $9 \mathrm{c}$ and $9 \mathrm{~d})$. This is also the pattern of movement previously 

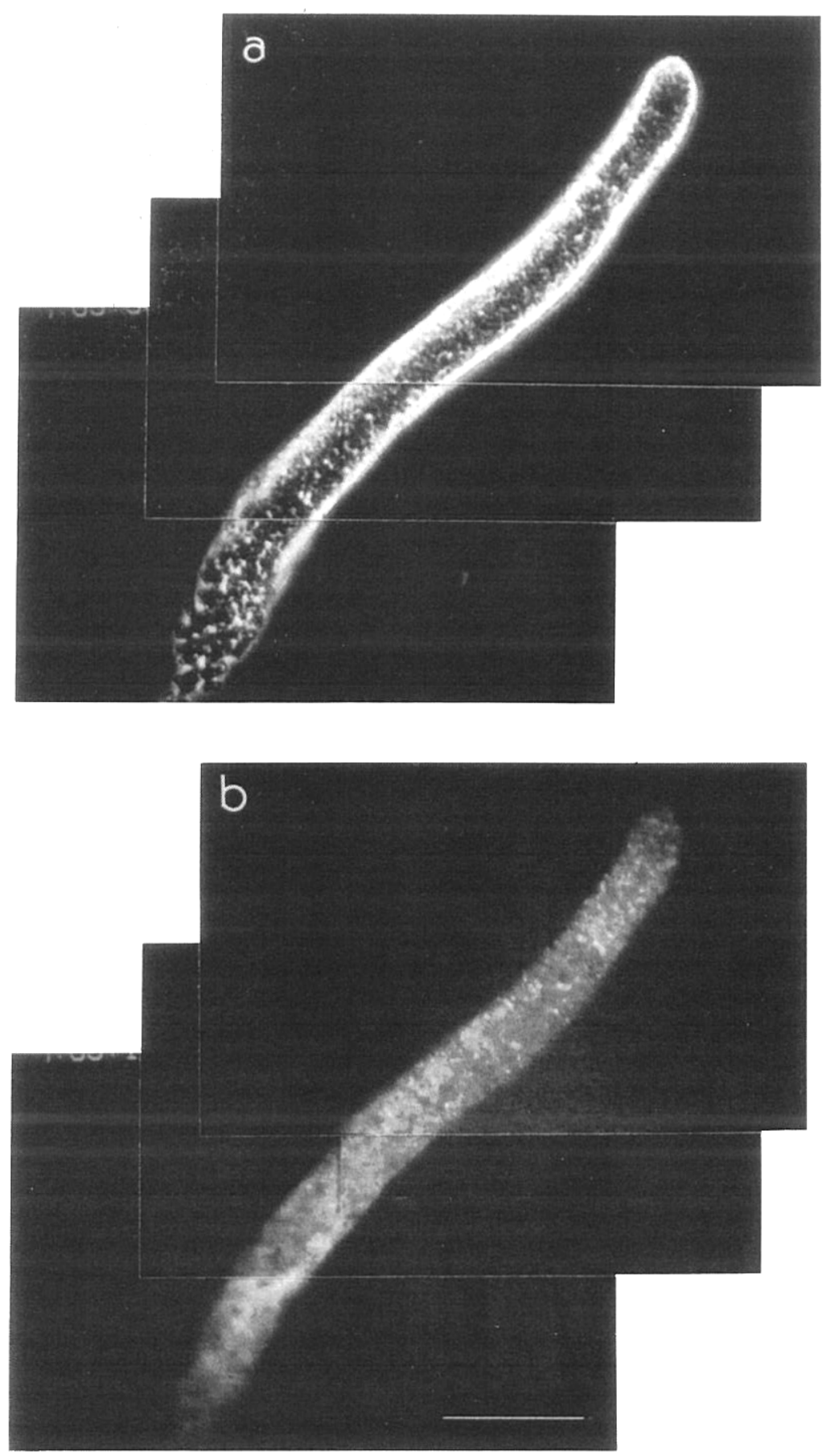

Figure 7. Analysis of the Behavior of Prespore Cells during Slug Migration

PspA-c-myc transformant cells were allowed to develop to the first finger stage of development, and the cells were subjected to in vivo labeling. This is a reformed slug viewed $16 \mathrm{hr}$ atter labeling (therefore after approximately $8 \mathrm{hr}$ of slug migration). (a) is the phase-contrast image, and (b) is the fluorescent image of the same field. The scale bar represents $100 \mu \mathrm{m}$. observed for neutral red stained ALCs within the prespore region (Siegert and Weijer, 1992).

The quantitative analysis of pstO/ALC movement in the prespore and prestalk zones compare very well with values obtained for movement rates of neutral red stained ALCs as determined by manual cell tracking (Table 1; Siegert and Weijer, 1992), suggesting that the various experimental manipulations and the prolonged illumination required for video recording have no detrimental effect on pstO/ALC movement. Again, as was observed for neutral red stained cells (Siegert and Weijer, 1992), the pstO/ ALCs within the rear of the slug move at the same velocity as all the other cells in the prespore zone, while pstol ALCs in the prestalk region move more rapidly.

We next analyzed the behavior of prespore cells that migrate forward into the prestalk zone to determine whether their movement patterns change upon translocation. pspA-c-myc transformant cells were in vivo labeled, and the resultant $p s p A^{*}$ slugs were allowed to migrate for several hours. After they move forward into the prestalk zone, 

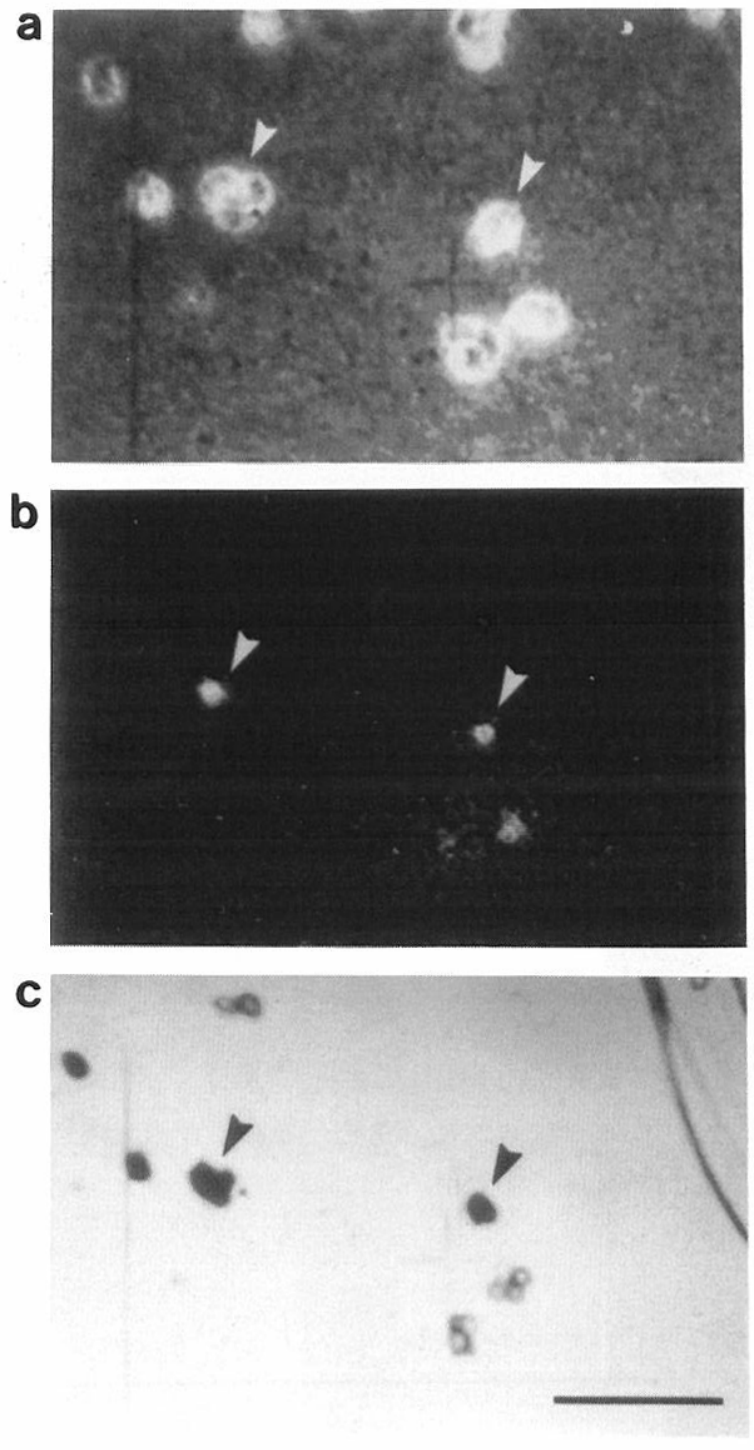

Figure 8. Analysis of Expression of the ecmO-lacZ Fusion Gene in pspa * Slugs

A double transformant strain was constructed containing the PSPAc-myc and the ecmO-lacZ fusion gene constructs. Slugs derived from this strain were subjected to in vivo labeling, and the cells were allowed to reaggregate to reform slugs ( $D s p A^{*}$ slugs). After $12 \mathrm{hr}$ of migration, the anterior halves of such slugs were excised and disaggregated. The dissociated cells were allowed to settle on a glass slide that was marked with a set of random scratches on its surface to allow for subsequent localization of the cells. After observation of the cells by fluorescence video microscopy, they were carefully fixed with $1 \%$ glutaraldehyde so that they did not change their positions on the substratum. They were then stained with $\mathrm{X}$-gal at $22^{\circ} \mathrm{C}$ for $12 \mathrm{hr}$. (a) shows a phase-contrast image of a selected field before $X$-gal staining, (b) shows the fluorescence image of the same field as in (a), and (c) shows the same field after staining with $X$-gal. The arrow heads indicate the fluorescently labeled cells that express the $\theta \mathrm{cmO}-\mathrm{lac} Z$ fusion gene. We interpret these to be cells that are expressing, or at some previous time had expressed, the pspA-c-myc fusion gene but that subsequently trans-differentiated to become pstO/ALCs. We routinely observed the strongest fluorescence in such trans-differentiated cells, presumably because the fluorescence label is better retained, concentrated within them, or both. At this level of sensitivity, the non-trans. differentiated prespore cells are poorly detectable but can just be seen, e.g., the two cells in the lower right hand part of the field. As expected, there are also celis, such as the two cells in the top left hand corner, the fluorescently labeled cells change their pattern of movement: from the linear, forward motion, typical of cells in the rear of the slug, to the ratational motion typical of prestalk cells (Figures $9 e$ and 9 ). Thus, their behavior precisely mimics that of the pstO/ALCs (compare Figures $9 \mathrm{~b}$ and $9 \mathrm{f}$ ), and they also move at similar velocities as the pstO/ALCs in the prestalk zone (Table 1). The fact that cells initially labeled in vivo with the prespore marker behave like pstO/ALCs when they move forward provides additional evidence for the trans-differentiation of prespore cells into pstO cells.

\section{Periodic Movement of Psto/ALCs}

A previous study showed that neutral red stained ALCs in the prespore zone move forward in a coherent fashion, with a periodicity of 2-3 min (Siegert and Weijer, 1992). It was not possible to trace individual neutral red labeled cells in the slug tip for long enough periods of time to determine whether they also move periodically because the cells move out of focus in less than $2 \mathrm{~min}$. Fluorescently labeled cells in the tip can be tracked for longer times than neutral red stained cells, hence we reinvestigated this question using in vivo labeling.

Periodicity cannot be detected with the vector field method because it determines average velocity; therefore, we analyzed cell movement of pstOIALCs in the prestalk region by manual cell tracking. The vector velocity field for the selected slug is shown in Figure 10a, while Figure $10 \mathrm{~b}$ shows the manually plotted tracks of the five pstO/ ALCs that happened to remain in focus during the observation period. Rotational cell movement of pstO/ALCs is evident from both figures. To show the displacement of the cells over time, we plotted the positions of the centers of each of the five selected cells at $5 \mathrm{~s}$ intervals (Figure 10c) and their movement rates versus time (Figure 10d). The relative separation of the symbols (Figure 10c) shows that the movement rates vary over time, the cells going through periods of fast movement (widely spaced symbols) followed by periods of slow movement (closely spaced symbols).

Autocorrelation analysis of the velocity measurements displayed in Figure 10d indicates that the cells move with a periodicity of approximately $90 \mathrm{~s}$ (data not shown). To show periodicity more clearly, it would be necessary to track single cells for longer periods of time. Unfortunately, this is not at present possible because the rotating cells in the tip move out of focus within 2 or $3 \mathrm{~min}$, the time it takes a cell to cross the diameter of the tip (se日 Figure 10b). Three-dimensional cell tracking will be required to solve this problem.

\section{Discussion}

We have established a method of marking specific Dictyostelium cell types that allows their movements to be

that express the ecmO-lacZ construct but that show no detectable fluorescence. We assume these to be cells that differentiated directly as pstO/ALCs. 

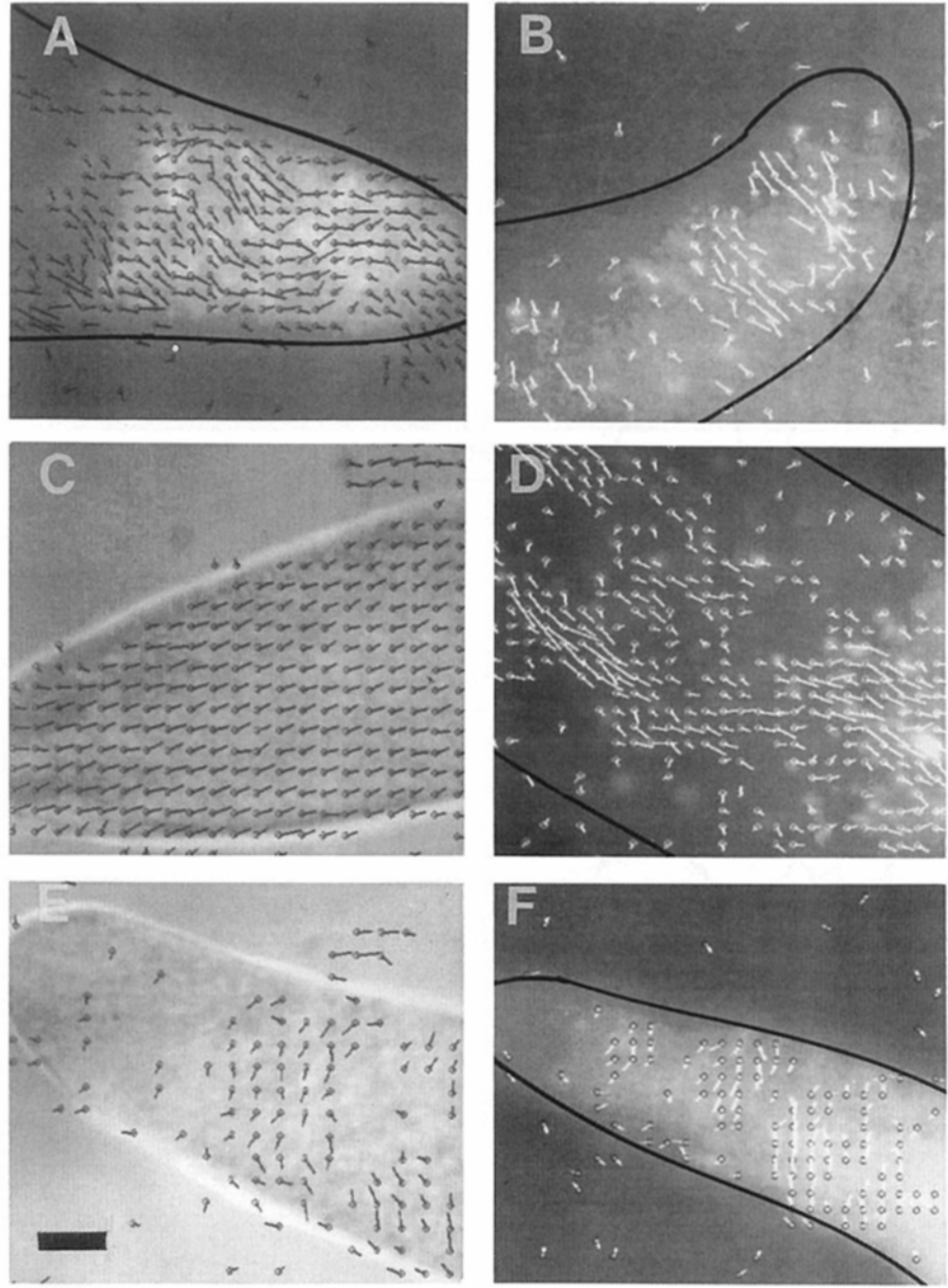

Figure 9. Analysis of the Movement Pattern of PstO/ALCs and of Prespore Cells in the Anterior and Posterior Regions of the Slug

(a) Movement of fluorescently labeled psiOI ALCs in the tip of a slug. This siug was moving from left to right. The velocities of $10 \times 10$ neighboring vectors are averaged (see Experimental Procedures), and only velocities of over $4 \mu \mathrm{m} / \mathrm{min}$ are shown. The starting point of each vector is indicated by a circle. The lengths of the vectors is shown in arbitrary units, but the same scale is used in all figures. Scale bar, $30 \mu \mathrm{m}$.

(b) Another example of pstO/ALC movement in the tip. The cells move in counter-rotating bands.

(c) Cell movement in the back of a slug, measured in transmitted light, showing that all cells move forward in the direction of slug migration. Approximately $90 \%$ of these cells are prespore cells, the remainder are ALCs (Sternfeld and David, 1982).

(d) Vector velocity field of fluorescently labeled pstO/ALCs in the back of a slug, showing that they move forward in the direction of slug $\mathrm{ml}-$ gration. This slug is migrating along the diagonal (from upper left to lower right corner) of the image.

(e) Velocity vector field for a slug tip in transmitted light. It shows that the prestalk cells move in counter-rotating bands.

(f) The movement of fluorescently labeled prespore cells in the psto region of the same slug as shown in (e). The cells show exactly the same movement as the cells in transmitted light. traced over extended periods of time. The method relies on the ability of Dictyostelium cells rapidly to recapitulate their development when the aggregate is mechanically disrupted. Dissociated cells labeled at their surfaces using a fluorescently tagged monoclonal antibody reaggregate and (remarkably, given the manipulations involved) retain their original identities: prestalk cells collect at the tip with the prespore cells below them. This apparent indelibility of sorting preference also extends to a subset of the prestalk cells, the psto cells. It is consistent with the notion that slug construction involves the differentiation of each component cell type at spatially separate positions within the aggregate, followed by movement to occupy their preferred position. However, our analysis also reveals there to be a degree of plasticity in cell fate if the slug undergoes migration.

Table 1. Quantitative Analysis of the Movement of PstOIALCs and of Prespore Cells

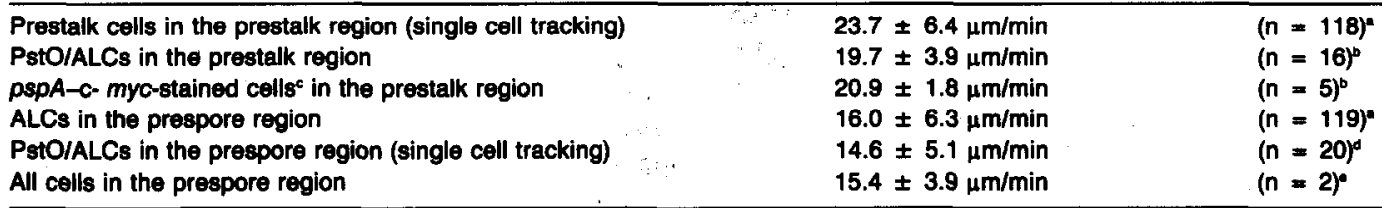

- Cells were detected by neutral red staining, and $n=$ the number of cells that were tracked (data from Siegert and Weijer, [1992]).

- $n=$ the number of separate experiments performed, using the fluorescence vector method (see Experimental Procedures).

"These are fluorescently labeled cells in pspA * slugs (see text).

- These data derive from manual, single cell tracking experiments in which $\mathbf{n}=$ the number of cells that were tracked.

- $n=$ the number of slugs analyzed by transmitted light using the vector method (see Experimental Procedures). 

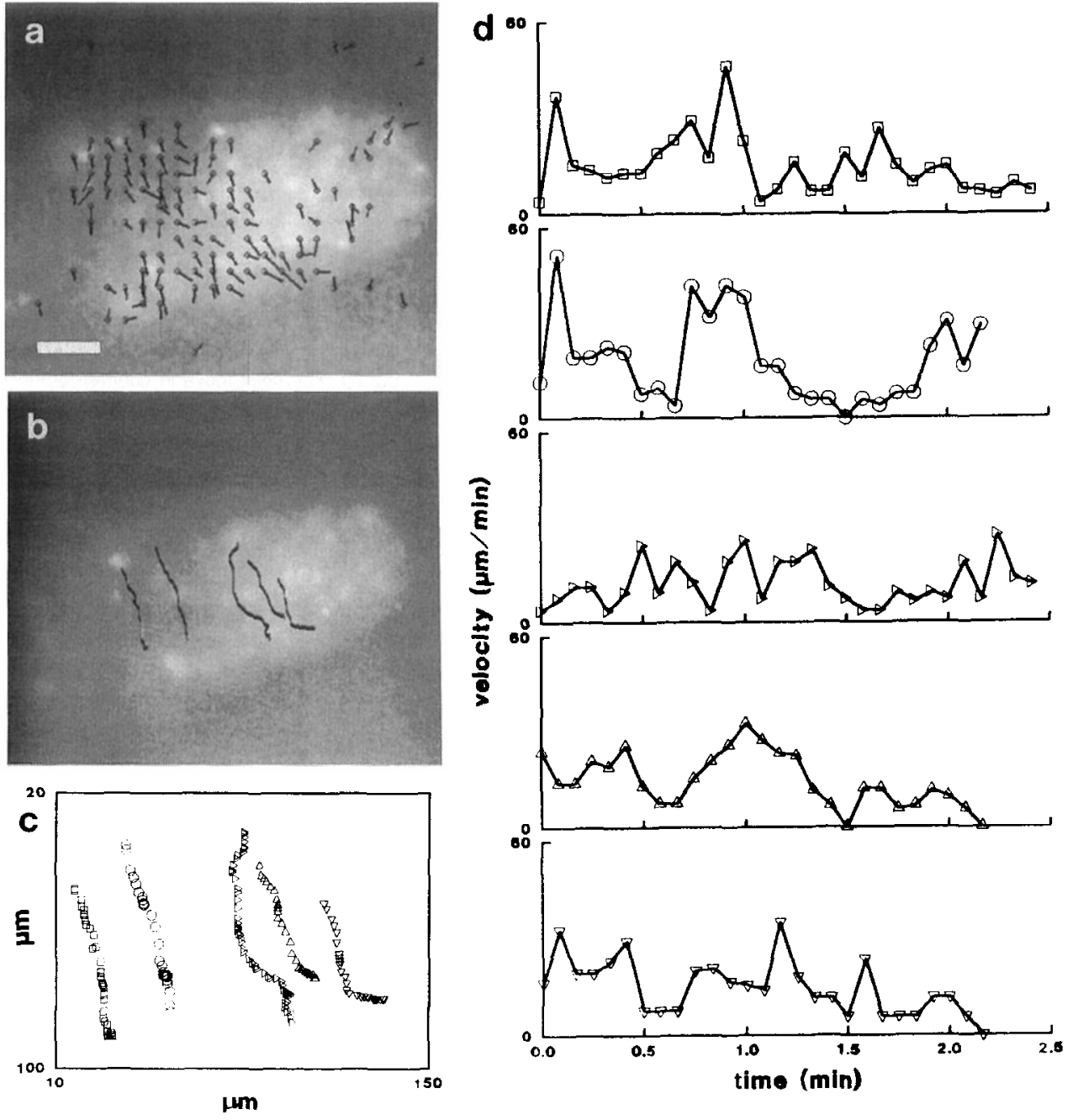

Figure 10. Analysis of the Movement of PstO/ALCs in the PstO Zone of the Tip

(a) Movement of fluorescently labeled pstO/ALCs in the tip of a slug. Only velocities of over $4 \mu \mathrm{m} / \mathrm{min}$ are shown. The velocities of $8 \times 8$ neighboring vectors are averaged. The cells show a simple rotational movement pattern. Scale bar, $30 \mu \mathrm{m}$.

(b) Tracks of five pstO/ALCs in the tip of the same slug shown in (a). Cells 2, 4, and 5 were tracked over a period of 2.5 min, while cells 1 and 3 were tracked over 4.2 min (numbering of the cells is from left to right).

(c) Tracks of the same five cells shown in (b) indicating their position at successive $5 \mathrm{~s}$ intervals. Each cell track is labeled with a different symbol. (d) The movement rates of each of the five cells shown in (b) and (c) as a function of time. The cells shown in (c), as disposed from left to right, are the same as shown in (d) but are disposed from top to bottom. The same symbols for the cells are used in (c) and (d). The average velocities of the cells (from left to right, i.e., 1-5) are as follows: $15.1 \mu \mathrm{m} / \mathrm{min}, 19.0 \mu \mathrm{m} / \mathrm{min}, 12.8 \mu \mathrm{m} / \mathrm{min}, 14.6 \mu \mathrm{m} / \mathrm{min}$, and $14.7 \mu \mathrm{m} / \mathrm{min}$.

A newly formed slug has discrete pstA and pstO regions within the tip, but after a time of migration, cells expressing (or that at some time previously had expressed) the ecmOlacZ fusion gene appear in the pstA region (Early et al., 1993). We have now shown that this is the result of forward cell movement because ecmO-expressing cells eventually become uniformly distributed throughout the prestalk region of a migrating slug. This observation illustrates the value of the in vivo labeling method because, using ecmospecific lacZ constructs, it was not possible to decide whether the uniform staining of the prestalk zone observed in slugs after extended periods of migration was the result of the forward movement of pstO cells or of the eventual "misactivation" of ecmO specifying regions of the ecmA promoter in pstA cells (Early et al., 1993). In vivo labeling thus provides a means to mark a cell indelibly at one point in its life history and to trace its subsequent movements.

We believe that there is unlikely to be an equivalent, compensatory reverse flow of pstA cells back ino the pstO region. Were there to be such a complete intermixing of the two cell types, migratory slugs containing the entire ecmA promoter fused to lac $Z$ would eventually display uniform staining throughout the prestalk zone. Since this is not the case (Jermyn and Williams, 1991), we believe that the pstA cells must remain predominantly located in the tip of the slug. There, they become intermixed with psto cells, as the pstO cells move forward during slug migration. The tip of the slug has one of the properties of an embry- 
onic organizer, in that it will cause formation of a secondary axis when transplanted to another slug (Raper, 1940; Rubin and Robertson, 1975), and it may be important to this function that the pstA cells remain as a discrete block within it.

The synergy experiment and the grafting experiment show that there is also movement of ecmo-expressing cells from the prespore to the prestalk regions during slug migration. The fact that the ecmo-expressing cells from the back of the slug are able to form a psto region after a reaggregation experiment or to join with a preexisting psto region in a grafting experiment leads us to believe that these may be the same cell type localized in different regions of the slug. We cannot of course rule out the possibility of a change in the pattern of gene expression but, until such a change in the state of cellular differentiation is found, we propose using a single term for both populations: pstO/ALC.

If there is a continual forward flow of pstO/ALCs from the prespore region to the pstO region and thence into the pstA region, how does the slug maintain the correct ratio of cell types? Part of the answer to this question is provided by a recent study of vitally stained cells within the migrating slug (Sternfeld, 1992). At culmination, pstA cells differentiate into pstAB cells at the entrance to the stalk tube, by activating expression of the $\theta \mathrm{cmB}$ gene (Jermyn and Williams, 1991). There exists within the migratory slug a core of pstAB cells located at the precise position where formation of the stalk tube is initiated at culmination (Jermyn et al., 1989; Jermyn and Williams, 1991). Using methylene blue, a vital dye that selectively stains pstAB cells, Sternfeld (1992) produced evidence for a unidirectional cell flow within the slug in which pstA cells first differentiate into pstAB cells and then fall behind into the slime trail where they differentiate into stalk cells.

Transplantation experiments, using cells marked by their expression of a non-cell type-specific reporter gene construct, support the above scheme. When cells from the pstA region are transferred into the pstO region, they initially return to the tip and then transitorily accumulate in the precise position occupied by the pstAB cells (Buhl and MacWilliams, 1991). If the discarded pstAB cells observed by Sternfeld (1992) were replenished from the pstO/ALCs via their differentiation first into pstA cells and then into pstAB cells, the gradual intermixing of pstO and psta cells would be explained. The pstO/ALCs in the anterior half of the prestalk zone would be cells that had transdifferentiated to become pstA cells. In such a scheme, cells in the pstO zone would act as intermediaries between the prespore and the prestalk (pstA) populations (Figure 11).

For the normal 1:4 ratio of prestalk to prespore cells to be maintained, such a cellular flow requires trans-differentiation of prespore cells, and there is evidence for this. When analyzed using a prespore-specific antiserum, the boundary between the prestalk and prespore regions becomes progressively eroded after prolonged periods of slug migration (Takeuchi et al., 1977). Furthermore, in a transformant containing a pspA-lacZ reporter gene, cells that were expressing (or that at some previous time had expressed) the fusion gene were found to accumulate in

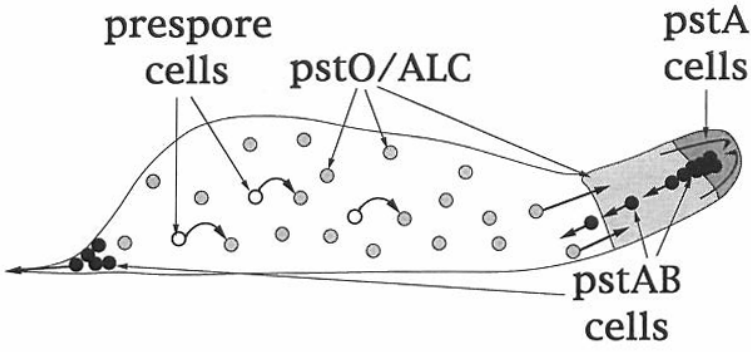

Figure 11. A Model for the Pattern of Cellular Flow and Redifferentiation within Migrating Slug

As the slug migrates forward, cells from within the core of pstAB cells within the tip are periodically left behind in the slime trail, perhaps during an abortive attempt at culmination. Here, the loss is shown as a dribble of celis since the pstAB core is often observed to trail backwards in this way (8ee for example Figure 3 in Jermyn et al. [1989]), but staining with vital dyes shows that the pstAB cells are sometimes lost as an entire cohort (Sternfeld, 1992). There is often a concentration of prestalk cells at the rear of the slug, which is termed the rearguard and here the rearguard is represented as a cluster of pstAB cells that are about to be shed into the trail. The discarded pstAB cells are replaced by pstA cells, which activate expression of the $\theta \mathrm{cmB}$ gene and so become pstAB cells. The pstA cells are replaced by pstO/ALCs from within the pstO region, which are, in turn, replaced from the reservoir of pstO/ALCs within the prespore region. The ultimate source of renewal are the prespore cells, which trans-differentiate into psto ALCs (this trans-differentiation being represented here by a curved arrow). For simplicities sake, this trans-differentiation is shown as occuring in situ within the prespore region, but we have no direct evidence to support this assumption.

the prestalk region during slug migration (Harwood et al., 1991). The pstO/ALCs are the obvious candidates for intermediates in prespore-prestalk trans-differentiation, and two pieces of evidence to support this notion are presented here. The fact that a subfraction of cells that are labeled via a prespore-specific marker (pspA* cells) eventually come to express an ecmO-specific construct shows that there is the potential for such a trans-differentiation to occur, and the fact that $\rho s p A^{*}$ cells migrate into the prestalk region during slug migration shows that there is a net forward flow of prespore cells.

Experiments using marked prestalk cells show that during normal slug migration the converse process, i.e., the conversion of a prestalk into a prespore cell, occurs only very rarely (Akiyama and Inouye, 1987). Thus, the mechanisms regulating cell type proportions within the slug seem designed to maintain the correct ratio of prespore to prestalk cells in the face of a gradual depletion of prestalk cells. One striking feature of the pattern of cellular flow and differentiation presented in Figure 11 is that the behavior of the prestalk cells within the slug foreshadows precisely their behavior during fruiting body formation, except that in the $D$. discoideum slug the differentiation of pstA into pstAB cells is a discontinuous rather than a continuous process. In other Dictyostelid species, such as D. mucoroides, that produce a stalk during slug migration, conversion is a continuous process (Gregg and Davis, 1982).

Our analysis of cell movement patterns within the slug confirms and extends previous results. The pstO/ALCs in the prespore region behave in exactly the same way as 
the ALCs detected using neutral red. In the prespore region, they move forward, in the direction of slug movement, at the same rate as the prespore cells themselves, but within the prestalk region they orbit around the long axis of the slug. Their movement is always rotational and can be explained by simple scroll waves of a propagating chemoattractant. We do not, however, exclude the possibility of chemoattractant waves of a more complicated geometry, such as twisted scroll waves, which would result in a tilted angle of rotation. Based upon the scheme in Figure 11, we believe that the translocated prespore cells are cells that have trans-differentiated into pstO/ALCs, and the fact that they acquire the same pattern of movement and velocity as pstO/ALCs if they move into the prestalk zone is consistent with this notion.

These results show there to be a surprisingly complex pattern of morphogenetic cell movement and redifferentiation during slug migration. Understanding these processes will require identification of the extracellular signals that direct cell migration and the intracellular response pathways that cause the various prestalk cell types to adopt their characteristic movement patterns. This in vivo labeling technique provides a means to study the first of these problems, and, because it can also be used as a method of purifying the different cell types (T. A. and J. W., unpublished data), it could facilitate investigation of the latter problem.

\section{Experimental Procedures}

\section{Growth and Development of Dictyostelium Cells}

Axenic cells (strain AX-2), were cultured in HL-5 medium (Watts and Ashworth, 1970), transformed by calcium phosphate coprecipitation, and maintained in medium containing $40 \mu \mathrm{g} / \mathrm{ml} \mathrm{G} 418$ (GIBCO) at $22^{\circ} \mathrm{C}$ on a rotary shaker. They were harvested at a density of $5 \times 10^{6}$ to $10 \times 10^{6} \mathrm{cells} / \mathrm{ml}$, washed by centrifugation, resuspended at a density of approximately $5 \times 10^{7} \mathrm{cells} / \mathrm{ml}$ in $\mathrm{KNa}_{2}$ buffer $\left(20 \mathrm{mM} \mathrm{KH} \mathrm{KO}_{4} /\right.$ $\mathrm{Na}_{2} \mathrm{HPO}_{4}[\mathrm{pH} 7.0]$ ), and spread in a streak on $2 \%$ nonnutrient agar plates. After $20-24 \mathrm{hr}$ of incubation in the dark at $22^{\circ} \mathrm{C}$, the slugs had migrated sufficiently far from their point of origin to be used for experiment.

\section{In Vivo Staining of Dissociated Slug Cells} with Fluorescent Antibody

Slugs were suspended in $\mathrm{KNa}_{2}$ and dissociated mechanically by passing them 10 times through a syringe needle (25G). The cells were washed once and resuspended at a density of $1 \times 10^{7}$ cells $/ \mathrm{ml}$ in $\mathrm{KNa}_{2}$ containing $0.1 \mathrm{mg} / \mathrm{ml}$ monoclonal antibody $9 \mathrm{E} 10$ (Evan et al., 1985) that was directly coupled to TRITC (Sigma) at an absorbance ratio of A555/A280 of 0.5 (Harlow and Lane, 1988) or to Texas Red (Molecular Probes Incorporated) at an A595/A280 absorbance ratio of 0.6. Direct coupling of 9E10 to the fluorochrome was found to be essential because detection with a secondary antibody drastically impaired cell motility. After a $\mathbf{3 0}$ min incubation in an ice bath, the cells were washed in $\mathrm{KNa}_{2}$, resuspended in $\mathrm{KNa}_{2}$, and streaked onto $2 \%$ nonnutrient agar. As a source of unlabeled cells for cell-mixing and grafting experiments, untransformed AX-2 slugs were treated in the same way but were not incubated with the $9 E 10$ antibody.

\section{Visualization of In Vivo Labeled Cells and Analysis} of Their Movement Patterns

For routine observation, slugs were periodically viewed with an inverted fluorescence microscope (Zeiss, Model ICM405) equipped with a low-light level video camera (Burle Incorporated, Model TC104OHX) or an image intensified CCD camera (Prostab Incorporated, Model HR604-MCP). To perform continuous observation of the living cells, transformant slugs were allowed to migrate on agar under mineral oil and were viewed with a more sensitive detection system (Siegert and Weijer, 1992). The microscope (Zeiss, Model IM35) was equipped with a computer controlled shutter, and video images were captured (normally at $5 \mathrm{~s}$ intervals) with a Silicon Intensified Target (SIT) camera (Hamamatsu Limited, Model C-2400). To reduce the exposure of slugs to light, the intensity of a $50 \mathrm{~W}$ mercury arc lamp was reduced 2- to 4-fold using neutral density filters, and the camera was adjusted to maximal sensitivity. Background noise was reduced by averaging 8-16 video images in real time (25 frames/s) before storing the result as a single image on a time-lapse video recorder (Sony, Model EVT-801CE). Digital image processing was performed with an ATcompatible computer equipped with an AFG board (Imaging Technology) at a resolution of $512 \times 512$ pixels.

\section{Analysis of Cell Movement Patterns}

The movement of individual cells was followed by an interactive, manual tracking procedure (Siegert and Weijer, 1992) or, alternatively, the movement of many cells was determined by a computer based image processing method from a series of consecutive digitized video images. This method allows calculation of the direction and rate of movement at every pixel in a $256 \times 256$ pixel area from 16 consecutive video images, resulting in a vector velocity field (Nomura ot al., 1991; Siegert and Weijer, 1992; Siegert et al., 1994). This vector field is displayed, superimposed on the first digitized image of the time series. This system allows the simultaneous display of the video sequence and the calculated vector field. For every pixel in the image, one vector is calculated. To reduce noise and improve the display of the vector field, several vectors in a square area ( $8 \times 8$ to $10 \times 10$ vectors) are averaged and the resultant averaged vector is displayed in the center of this square field. On the screen, the origin of each vector is indicated by a circle. The lengths of the vectors reflects the velocity detected at that location and the vector indicates the direction of cell movement. Before processing, each image of the series used for the calculation of the vector field is normalized to the average intensity of the first frame and then low-pass filtered to reduce noise.

\section{Acknowledgments}

We would like to thank David Traynor for help in making the ecmAc-myc construct, and we would also like to thank John Bonner for his insightful comments on an earlier version of this paper.

Received February 8, 1994; revised April 5, 1994.

\section{References}

Akiyama, Y., and Inouye, K. (1987). Cell type conversion in normally proportioned and prestalk enriched populations of slug cells in Dictyostelium discoideum. Differentiation 35, 83-87.

Blaschke, A., Weijer, C., and MacWillams, H. (1986). Dictyostelium discoideum cell type proportioning, cell differentiation preference, cell fate, and the behavior of anterior-like cells in HS1/HS2 and G+/Gmixtures. Differentiation 32, 1-9.

Bonner, J. (1952). The pattern of differentiation in amoeboid slime molds. Am. Nat. 86, 79-89.

Bonner, J. (1957). A theory of the control of differentiation in the cellular slime molds. Quart. Rev. Biol. 32, 232-246.

Buhl, B., and MacWilliams, H. (1991). Cell sorting within the prestalk zone of Dictyostelium-discoideum. Differentiation 46, 147-152.

Ceccarelli, A., Mahbubani, H., and Williams, J. G. (1991). Positively and negatively acting signals regulating stalk cell and anterior-like cell differentiation in Dictyostelium. Cell 65, 983-989.

Chung, S., Landfear, S. M., Blumberg, D., Cohen, N. S., and Lodish, H. F. (1981). Synthesis and stability of developmentally regulated mRNAs are affected by cell-cell contact and cAMP. Cell 24, 785-797.

Devine, K. M., and Loomis, W. F. (1985). Molecular characterization of anterior-like cells in Dictyostelium discoideum. Dev. Biol. 107, 364372.

Early, A. E., and Williams, J. G. (1989). Identification of DNA sequences regulating the transcription of a Dictyostelium gene selectively expressed in prespore cells. Nucl. Acids Res. 17, 6473-6484. 
Early, A. E., Williams, J. G., Meyer, H. E., Por, S. B., Smith, E., Williams, K. L., and Gooley, A. A. (1988). Structural characterization of Dictyostelium discoideum prespore-specific gene D19 and of its product, cell surface glycoprotein PsA. Mol. Cell. Biol. 8, 3458-3466.

Early, A. E., Gaskell, M. J., Traynor, D., and Williams, J. G. (1993). Two distinct populations of prestalk cells within the tip of the migratory Dictyostelium slug with differing fates at culmination. Development $118,353-362$.

Evan, G. I., Lewis, G. K., Ramsay, G., and Bishop, J. M. (1985). Isoletion of monoclonal antibodies specific for human c-myc proto-oncogene product. Mol. Cell. Biol. 5, 3610-3616.

Francis, D., and O'Day, D., (1971). Sorting out in pseudoplasmodia of Dictyostelium discoideum. J. Exp. Zool. 176, 265-272.

Gaskell, M., Watts, D., Treffry, T., Jermyn, K. A., and Williams, J. G. (1992). Immuno-localization and separation of multiple prestalk cell types in Dictyostellum. Differentiation 51, 171-176.

Gregg. J. H., and Davis, R. W. (1982). Dynamics of cell redifferentiation in Dictyostelium mucoroides. Differentiation 21, 200-205.

Gregg, J., Krefft, M., Haaskraus, A., and Williams, K. (1982). Antigenic differences detected between prespore cells of Dictyostelium discoideum and Dictyostelium mucoroides using monocional antibodies. Exp. Cell Res. 142, 229.

Hadwiger, J. A., and Firtel, R. A. (1992). Analysis of G alpha 4, a G-protein subunit required for multicellular development in Dictyostelium. Genes Dev. 6, 38-49.

Harlow, E., and Lane, D. (1980). Antibodies: A Laboratory Manual. (Cold Spring Harbor, New York: Cold Spring Harbor Laboratory Press), pp. 354-355.

Harwood, A., Early, A., Jermyn, K., and Williams, J. G. (1991). Unexpected localization of cells expressing a prespore marker of Dictyoste/ ium-discoideum. Differentiation 46, 7-13.

Howard, P. K., Setton, M. B., and Firtel, R. A. (1992). Analysis of a spatially regulated phosphotyrosine phosphatase identifies tyrosine phosphorylation as a key regulatory pathway in Dictyostelium. Cell 71, $637-647$.

Jermyn, K. A., and Williams, J. G. (1991). An analysis of culmination in Dictyostelium using prestalk and stalk-specific cell autonomous markers. Development 111, 779-787.

Jermyn, K. A., Duffy, K., and Williams, J. G. (1989). A new anatomy of the prestalk zone of Dictyostelium. Nature 340, 144-146.

Kakutani, T., and Takeuchi, I. (1986). Characterization of anterior-like cells as analyzed by their movement. Dev. Biol. 115, 439-445.

McRobbie, S., Tilly, R., Blight, K., Ceccarelli, A., and Williams, J. G. (1988). Identification and localization of proteins encoded by two DIF inducible genes of Dictyostelium. Dev. Biol. 125, 59-63.

Montell, D. J., Rorth, P., and Spradling, A. C. (1992). Slow border cells, a locus required for a developmentally regulated cell migration during oogenesis encodes Drosophila C/EBP, Cell 71, 51-62.

Niehrs, C., Keller, R., Cho, K. W. Y., and De Robertis, E. M. (1992) The homeobox gene goosecoid controls cell migration in Xenopus embryos. Cell 72, 491-504.

Nomura, A., Miike, H., and Koga, K. (1991). Field theory approach for determining optical flow. Pattern Recognition Lett. 12, 183-190.

Raper, K. B. (1940). Pseudoplasmodium formation and organisation in Dictyostelium discoideum. J. Elisha Mitchell Sci. Soc. 59, 241-282. Raper, K. B., and Fennell, D. I. (1952). Stalk formation in Dictyostelium. Bull. Torrey Bot. Club 79, 25-51.

Rubin, J., and Robertson, A. (1975). The tip of the Dictyostelium discoideum pseudoplasmodium as an organizer. J. Embryol. Exp. Morphol. 33, 227-241.

Salser, S. J., and Kenyon, C. (1992). Activation of a C. elegans Antennapedia homologue in migrating cells controls their direction of migration. Nature 355, 255-258.

Siegert, F., and Weijer, C. (1991). Analysis of optical-density wavepropagation and cell-movement in the cellular slime-mold Dictyostelium-discoideum. Physica [D] 49, 224-232.

Siegert, F., and Weijer, C. (1992). Three dimensional scroll waves organise Dictyostellum slugs. Proc. Natl. Acad. Sci. USA 89, 6433-
6437

Siegert, F., Weijer, J., Nomura, A., and Miike, H. (1994). A gradientmethod for the quantitative-analysis of cell-movement and tissue flow and its application to the analysis of multicellular Dictyostelium development. J. Cell Sci., 107, 97-104.

Steinbock, O., Siegert, F., Muller, S. C., and Weijer, C. J. (1993). Three dimensional waves of excitation during Dictyostelium morphogenesis. Proc. Natl. Acad. Sci. USA 90, 7332-7335.

Sternfeld, J. (1992). A study of pstB cells during Dictyostelium migration and culmination reveals a unidirectional cell type conversion pro. cess. Roux's Arch. Dev. Biol. 201, 354-363.

Sternfeld, J., and David, C. N. (1981). Cell sorting during pattern formation In Dictyostellum. Differentiation 20, 10-20.

Sternfeld, J., and David, C. N. (1982). Fate and regulation of anteriorlike cells in Dictyostelium slugs. Dev. Biol. 93, 111-118.

Takeuchi, I., Hayashi, M., and Tasaka, M. (1977). Cell differentiation and pattern formation in Dictyostelium. In Development and Differentiation in the Cellular Slime Moulds, P. Cappuccinelli and J. M. Ashworth, eds. (Amsterdam: Elsevier/North Holland Biomed Press), pp. 1-16. Ti, Z., Gooley, A., Slade, M., Bowers, V., and Williams, K. (1990). Purification of a membrane glycoprotein with an inositol-containing phospholipid anchor from dictyostelium-discoideum. J. Biotechnol. 16, 233-244.

Watts, D. J., and Ashworth, J. M. (1970). Growth of myxamoebae of the cellular slime mould Dictyostelium discoideum. Biochem. J. 119, 171-174.

Williams, J. G., Dutfy, K. T., Lane, D. P., McRobbie, S. J., Harwood, A. J., Traynor, D. T., and Jermyn, K. A. (1989). Origins of the prestalkprespore pattern in Dictyostelium development. Cell 59, 1157-1163. 